\title{
Avaliação das Competências Docentes: Análise no Curso de Ciências Contábeis da UTFPR
}

\begin{abstract}
Resumo
As competências relacionadas à docência universitária englobam conhecimentos, habilidades e atitudes que seus profissionais necessitam para exercer adequadamente seu trabalho. A avaliação de tais competências pode permitir ao professor refletir sua postura perante os discentes, e, embora tal procedimento seja complexo, seus resultados podem ser importantes para a melhoria da qualidade do ensino. Nesse contexto, o presente estudo objetivou identificar o nível de satisfação e expectativa dos alunos em relação aos professores do curso de Ciências Contábeis da Universidade Tecnológica Federal do Paraná (UTFPR), Campus Pato Branco. A pesquisa se caracteriza como descritiva e quantitativa e a coleta de dados foi realizada por meio de questionários aplicados aos acadêmicos do curso. Os principais resultados da pesquisa são: (i) os discentes têm uma maior expectativa (média 9,1) dos docentes quando comparado com a satisfação (média 6,9); (ii) as competências com melhores avaliações pelos discentes são: relacionamento interpessoal, comprometimento, domínio da área, ética e didático-pedagógico; (iii) as competências com as piores avaliações pelos discentes são: comunicação, flexibilidade, empatia, criatividade e trabalho em equipe; $\mathrm{e}$ (iv) o gênero feminino apresenta maior expectativa dos docentes quando comparado com o gênero masculino. As principais implicações/conclusões do presente estudo são: (i) o presente estudo não apresenta divergências significativas em relação aos estudos precedentes; (ii) os professores do curso em estudo e de cursos similares devem estar atentos às competências com pior nível de satisfação; (iii) o nível geral de expectativa do aluno é bem superior à satisfação e isso deve ser considerado pelos professores no planejamento de suas disciplinas; e (iv) as competências com menor nível de satisfação dos alunos referem-se às dimensões atitudes e habilidades e não de conhecimento. Tal conclusão é fundamental para que o professor tenha ciência que o aluno valoriza outras dimensões e, não somente, o conhecimento. Além disso, tais resultados servem também para que os cursos e coordenações considerem tais competências em seus planejamentos de capacitações.
\end{abstract}

Palavras-Chave: Competência. Satisfação. Expectativa. Educação.

\section{Patricia Zanella}

Pós-graduada em Gestão Financeira, Controladoria e Auditoria pela Universidade Tecnológica Federal do Paraná (UTFPR) e Auxiliar em Escrita Fiscal no Centro Contábil Empresarial e Agroempresarial (Ceceagro). Contato: Rua Candido Merlo, Centro, Bom Sucesso do SUI/PR, CEP: 85515-000.

E-mail: patrícia_zanella_99@hotmail.com

Ricardo Adriano Antonelli Mestre em Contabilidade pela Universidade Federal do Paraná (UFPR) e Professor na Universidade Tecnológica Federal do Paraná (UTFPR). Contato: Campus Pato Branco, Via do Conhecimento, Km1, Pato Branco/PR, CEP: 85503-390.

E-mail: ricardoaantonelli@yahoo.com.br

Sandro César Bortoluzzi Doutor em Engenharia de Produção pela Universidade Federal de Santa Catarina (UFSC) e Professor na Universidade Tecnológica Federal do Paraná (UTFPR). Contato: Campus Pato Branco, Via do Conhecimento, Km1, Pato Branco/PR, CEP: 85503-390.

E-mail: sandro@utfpr.edu.br 


\section{Introdução}

As universidades são propulsoras do desenvolvimento de um país, pois, além de fornecer pessoas aptas ao mercado de trabalho, também têm papel na formação de pessoas críticas em relação aos principais temas de interesse da sociedade, como a cultura, política e economia (Fava de Moraes, 2000). Nesse contexto, em que a universidade se destaca na formação de pessoas, necessita-se de discussões acerca da avaliação do docente, pois, segundo Apio e Silvino (2013), os docentes são os principais responsáveis pelo processo de ensino-aprendizagem. Os autores afirmam que a maior preocupação de uma Instituição de Ensino Superior (IES) deve estar voltada à qualidade do ensino e, ainda, deve-se assumir que o desempenho dos docentes em sala de aula seja uma das variáveis de maior impacto no processo ensino-aprendizagem.

No entanto, o processo de avaliação de desempenho do docente é complexo e tem demandado das IES o aprimoramento constante dos seus instrumentos e técnicas, conforme citado por Apio e Silvino (2013). Além disso, Miranda, Casa Nova e Cornacchione Junior (2014) citam que a avaliação das qualificações docentes tem sido um tema recorrente na literatura e, não, sem controvérsias.

Apesar da complexidade, muitos autores acreditam que o processo de avaliação docente é um importante instrumento para a melhoria da qualidade do ensino (Castanheira \& Ceroni, 2007). Segundo os autores, a avaliação do docente é um importante meio de diagnóstico de seu trabalho. No entanto, alertase que a avaliação é utilizada apenas para fins de verificação e não apresenta efeitos na dinâmica da ação pedagógica conduzida pelo professor (Luckesi, 2002). Nesse sentido, vários autores argumentam que a avaliação deve ir além de o simples fato de avaliar/verificar (Luckesi, 2002; Ribeiro, 2012; Apio \& Silvino, 2013), de modo que ela deva ser também um instrumento que permita ao professor repensar sua postura perante os resultados, além de ser inclusiva, acolhedora e integrativa (Luckesi, 2002).

Sendo assim, Ribeiro (2012) aborda algumas atitudes dos docentes após o processo de avaliação: (i) refletir sobre o resultado; (ii) discutir com os alunos o resultado do processo avaliativo; (iii) com tais resultados, buscar modificações em sua atuação; e (iv) interessar-se somente pelo resultado positivo, ignorando o negativo. $\mathrm{O}$ autor salienta que, na pesquisa realizada, não foi identificado depoimento que indicasse uma postura de negação do docente após receber o resultado, ou seja, o professor, ao receber o resultado da avaliação, toma uma decisão de aperfeiçoamento no desempenho. $\mathrm{O}$ autor ainda complementa que em pesquisas realizadas com professores de IES públicas, apareceram elementos que indicam a presença de atitude de refletir sobre os resultados da avaliação, para que, posteriormente, sejam implementadas melhorias da ação pedagógica. Com isso, faz-se necessário discutir as dimensões, variáveis e formas de realizar a avaliação docente. Nesse sentido, Antonelli, Colauto e Cunha (2012) relatam que uma forma de avaliar a qualidade do ensino é por meio da relação expectativa/satisfação dos alunos em relação às competências docentes.

Segundo Grohmann e Ramos (2012), o termo "competência docente" é empregado nas pesquisas que abordam a qualidade do ensino, satisfação dos docentes e discentes. Adicionalmente, os autores informam que a ideia de competência possui duas correntes principais: a corrente americana, que considera a competência como um conjunto de conhecimentos, habilidades e atitudes; e a corrente europeia, que entende que as competências são demonstradas a partir do momento em que os professores atingem ou superam resultados esperados em seu trabalho. Cabe salientar que o presente trabalho segue a corrente americana, a qual entende a competência como um conjunto de conhecimentos, habilidades e atitudes.

Com a atenção voltada à qualidade do ensino, é importante que as IES realizem a avaliação dos seus docentes, a fim de verificar se estes estão atendendo às necessidades e expectativas de seus discentes, obtendo, assim, um feedback para que busquem melhoria contínua, culminando com a crescente qualidade no ensino. Diante do exposto, este trabalho tem como problema de pesquisa: qual é o nível de satisfação e expectativas dos alunos do Curso de Ciências Contábeis da Universidade Tecnológica Federal do Paraná (UTFPR) - Campus Pato Branco, em relação aos seus docentes? Desse modo, o estudo tem como objetivo principal avaliar o grau de satisfação e de expectativa dos estudantes do curso de Ciências Contábeis da UTFPR com relação às competências docentes. 
A presente pesquisa se justifica pela contribuição teórica e prática em relação ao tema "Avaliação das Competências Docente". Em relação à contribuição teórica, destaca-se a replicação de mais um estudo em um contexto complexo e com inúmeras necessidades de aperfeiçoamento, como as competências docentes e, consequentemente, a qualidade do ensino. Destaca-se também como contribuição teórica os achados da presente pesquisa e o cotejamento realizado com pesquisas precedentes, pois revela que mesmo com o passar do tempo, muitas competências docentes são negligenciadas no processo de planejamento da disciplina, além do processo de planejamento das capacitações disponibilizadas pelas coordenações de curso e pelas instituições de ensino.

Em relação à contribuição prática, destaca-se a utilidade do estudo para o curso analisado, pois poderá fomentar ações de melhoria que contribuam com a qualidade do ensino. Essa contribuição prática alcança os alunos do curso, os professores e a direção da universidade, que podem analisar os resultados com o propósito de melhorar o processo de ensino-aprendizagem, pois, conforme citado por Lima, Oliveira, Araújo e Miranda (2015), muitos dormem contadores e acordam professores, ingressando no ensino universitário sem nenhuma formação pedagógica, o que, muitas vezes, os obriga a aventurar-se em uma docência de ensaio e erro por muitos anos. Na mesma linha, Miranda et al. (2014) afirmam que os professores do ensino superior, em geral, não passam por uma preparação pedagógica sistematizada para o exercício da docência. Ademais, o estudo delimita-se ao curso superior de Ciências Contábeis da UTFPR. Sendo assim, destaca-se que os resultados apresentados têm validade para o curso analisado. No entanto, o instrumento de coleta de dados poderá ser replicado a outros cursos e universidades.

\section{Referencial Teórico}

\subsection{Aspectos conceituais de competências}

A conceituação de competências tem sido estudada e revista por vários autores, como Parry (1996), McLagan (1997), Hipólito (2000), Fleury e Fleury (2001), Bitencourt (2001), Sant’anna (2002), Silva (2003) entre outros. Para Fleury e Fleury (2001), a palavra competência faz parte do senso comum, aplicada quando um indivíduo tem capacidade de realizar alguma tarefa, ou seja, a competência está relacionada com capacidade ou conhecimento das pessoas sobre determinado assunto.

No meio acadêmico, McClelland (1973) deu início ao debate em torno das competências, definida como uma característica subjacente a uma pessoa que é casualmente relacionada com o desempenho superior na realização de uma tarefa, ou de determinada situação. O autor diferencia as competências de habilidades, sendo os talentos particulares adquiridos por meio da prática do dia a dia; aptidão, que seria o talento natural de cada pessoa; e conhecimento, que é o que a pessoa deve saber para se realizar determinada tarefa (Fleury \& Fleury, 2001).

Segundo Perez (2005), o tema competência começou a ser usado de forma pragmática, na França e nos grandes países capitalistas, especialmente em locais de trabalho de empresas de ponta. Já no Brasil, a autora indica que o tema emergiu inicialmente na academia, e, posteriormente, tem sido adotado de forma experimental pelas empresas. A importância das competências já era prevista por Zarafin (2001), ao indicar que a virada havia começado, em que a lógica da competência iria impor-se com ou sem negociações.

Considerando a literatura disponível, Fleury e Fleury (2001) buscaram realizar uma abordagem mais eficaz para a avaliação das competências das pessoas selecionadas para trabalhar nas organizações, pois, nos exames até então utilizados, não era possível avaliar o sucesso do indivíduo no trabalho e no decorrer de suas vidas. Boyaltzis (2004 apud Pereira, 2007) analisou as dimensões das competências e concluiu que, para uma melhor compreensão, elas devem ser analisadas na seguinte ótica: conhecimento (pelo que precisa ser feito); habilidade (como deve ser realizada determinada tarefa); e atitude (por que deve ser feito). Ao existir a combinação desses três elementos, o indivíduo se torna apto para determinada função e traz os resultados desejados pela organização. 
Durand (1998) conceituou "competência" como um conjunto de conhecimentos, habilidades e atitudes interdependentes e necessárias ao desenvolvimento de objetivo específico. Segundo ele, o indivíduo, quando realiza um trabalho, exerce, simultaneamente, esse conjunto de competência e, não, uma de cada vez. Nos estudos de competências, em geral, duas dimensões são estudadas: individual e organizacional. Para Filenga, Moura e Rama (2010), as competências individuais têm tido em maior atenção nas pesquisas, porém, ambas são importantes, pois, conforme ponderado por Dutra (2008), para o estabelecimento das competências individuais, é necessária uma reflexão vinculada com as competências organizacionais, dada a influência mútua entre elas. Na mesma linha, Fleury e Fleury (2001) complementam indicando que o conjunto de competências individuais desenvolvidas e as estratégias do negócio formam as competências essenciais para a organização.

Diante do exposto, na literatura é possível encontrar pesquisas com o foco nas competências organizacionais, como Hamel e Prahalad (1995) e Ruas, Antonello e Boff (2005), cujas competências foram relacionadas com as organizações. Para Ruas et al. (2005), o conceito de competência está relacionado, por um lado, com a missão, visão e estratégias competitivas das empresas e, por outro lado, com as competências individuais. Enquanto isso, Hamel e Prahalad (1995) dizem que se as empresas identificarem e desenvolverem suas competências, no futuro tendem a ter maior sucesso.

No âmbito individual, as competências estão relacionadas com as habilidades que cada pessoa tem em realizar determinado trabalho, que, conforme Medeiros e Oliveira (2009), é associado ao saber agir, mobilizar-se, aprender, transferir os conhecimentos, engajar-se, ter visão estratégica e assumir responsabilidades. Sendo assim, é necessário que as pessoas possam colocar em prática suas competências para que cada vez mais consiga aperfeiçoá-las. Para Pereira (2007, pp. 63), as competências individuais são descritas como "características de uma pessoa e que estão relacionadas ao seu desempenho em qualquer atividade profissional". Contudo, a avaliação das competências individuais se dá por meio da relação existente entre as tarefas e cargos ocupados pelas pessoas. Seguindo essa linha de pensamento, "gestão por competência" é apenas um rótulo mais moderno para administrar uma realidade organizacional ainda fundada nos princípios do taylorismo-fordismo (Fleury \& Fleury, 2001).

Considerando que as competências individuais são a base de formação para as competências organizacionais, as quais possuem mútua influência, conforme ponderado por Dutra (2008), infere-se que a organização prepara o indivíduo para enfrentar novas situações tanto organizacionais quanto pessoais, enquanto por outro lado, o indivíduo oferece à organização seu aprendizado para que essa consiga enfrentar seus desafios.

Em tal contexto, conforme Filenga, Moura e Rama (2010), na literatura há um consenso que a aprendizagem é um ponto chave, de modo que, é considerada a mola propulsora do desenvolvimento das competências, conforme corrobora Souza (2005). Nesse sentido, Hamel e Prahalad (1995) introduziram o conceito de core competence (competência essencial), no qual destacam que as empresas com maior sucesso serão as que melhor identificarem e desenvolverem suas competências, fazendo com que sua competitividade aumente em relação aos seus concorrentes. No estudo de Hamel e Prahalad (1995), o conceito de core competence é definido como um conjunto de habilidades e tecnologias, não se tratando de uma única habilidade e tecnologia isolada que permitem a organização oferecer um benefício fundamental único ao cliente. Além disso, para os autores, uma competência essencial é assim considerada quando se constitui como a base para a entrada em novos mercados de produtos.

Desse modo, a presente pesquisa consiste em analisar as competências relacionadas ao indivíduo, fundamentando-se nas competências docentes sob a avaliação dos discentes do curso de Ciências Contábeis. 


\subsection{Competências dos docentes}

Muitos são os conceitos para competência, conforme já descritos, sendo que, para Pereira (2007, pp. 83), as competências de um docente universitário "é o conjunto de conhecimentos, habilidades e atitudes interdependentes e necessárias para o exercício das atividades de ensino e pesquisa na educação superior". Dessa forma, os professores necessitam cada vez mais de um amplo conhecimento sobre os assuntos ministrados em sala de aula, para poder atender às expectativas de seus alunos. Portanto, para que o professor possa tratar, de forma clara, o conteúdo trabalhado em sala de aula, é indispensável que não meça esforços para o desenvolvimento das competências necessárias ao ensino-aprendizagem dos alunos.

\subsubsection{Conjunto de competência dos docentes}

A Contabilidade como uma ciência social aplicada é afetada pelas mudanças ocorridas no ambiente, sendo conhecida como a linguagem dos negócios e deve ter seu ensino focado no aspecto mutável que a ciência traz consigo (Vasconcelos, 2009). Antonelli et al. (2012) destacam duas definições importantes de competência da literatura: a faculdade de mobilizar um conjunto de recursos cognitivos, como saberes, capacidades, informações, entre outros, para solucionar com pertinência e eficácia uma série de situações (Perrenoud, 2000); e um conjunto de conhecimentos, habilidades e atitudes interdependentes e necessárias para o desenvolvimento de propósitos predefinidos (Durand, 1998).

No estudo realizado por Durand (1998), as competências estão agrupadas em três dimensões: Conhecimento, Habilidades e Atitudes.

A dimensão do conhecimento engloba tudo o que é aprendido nas salas de aula, no dia a dia do trabalho, na convivência com outras pessoas e que é levado para a vida pessoal e profissional de cada indivíduo. Para Vasconcelos (2009, pp. 57), "o Conhecimento pode ser entendido como uma série de informações assimiladas pelo ser humano ao longo de sua vida, a partir de suas experiências vivenciadas em educação formal ou treinamentos específicos".

A Habilidade, segundo Vasconcelos (2009, pp. 57), "está relacionada ao saber como fazer, a colocar em prática as informações adquiridas ao longo da vida, em situações práticas". Dessa maneira, entende-se que a habilidade está relacionada com o saber transformar em prática todos os seus conhecimentos adquiridos durante sua vida acadêmica e profissional, a fim de resolver determinadas situações.

Já a dimensão das atitudes está relacionada com a forma de agir, com os sentimentos e a forma de se relacionar de cada pessoa. Para Pereira (2007, pp. 85), a atitude é "relacionada com o saber comportamental, relacionado com a disposição do indivíduo em querer fazer alguma coisa, normalmente ligado a aspectos de campo social ou afetivo". Contudo, trabalhando com pessoas que tenham mais afinidades, as atitudes podem ser outras, pois a comunicação e interação entre elas são melhores do que com uma pessoa, cujo nível íntimo seja menor.

Com isso, podem ser relacionadas quatorze competências necessárias para os docentes, embasadas no estudo de Pereira (2007) e agrupadas nas três dimensões de Durand (1998), as quais foram utilizadas por Antonelli et al. (2012), relacionadas na Tabela 1. 
Tabela 1

Competências Necessárias à Atividade Docente de Ensino

\begin{tabular}{|c|c|c|}
\hline Dimensão & Competência & Definição da Competência \\
\hline \multirow[b]{2}{*}{ Conhecimento } & Domínio área de conhecimento & $\begin{array}{l}\text { É a capacidade de possuir conhecimentos sólidos em } \\
\text { uma área específica, bem como experiência profissional } \\
\text { adquirida por meio da pesquisa científica. }\end{array}$ \\
\hline & Didático-Pedagógica & $\begin{array}{l}\text { É o conhecimento de conceitos fundamentais didático- } \\
\text { pedagógicos, adquirido por meio de cursos e/ou } \\
\text { treinamentos específicos. }\end{array}$ \\
\hline \multirow{7}{*}{ Habilidades } & Relacionamento interpessoal & $\begin{array}{l}\text { É a capacidade de estabelecer um relacionamento } \\
\text { harmônico e saudável com os seus alunos, inclusive } \\
\text { sabendo administrar de forma equilibrada as eventuais } \\
\text { situações conflitantes que possam surgir. }\end{array}$ \\
\hline & Trabalho em equipe & $\begin{array}{l}\text { É a capacidade de cooperar e obter cooperação de seus } \\
\text { colegas nas atividades de ensino com objetivos comuns. }\end{array}$ \\
\hline & Criatividade & $\begin{array}{l}\text { É a capacidade de criar soluções inovadoras na } \\
\text { condução do processo ensino-aprendizagem. }\end{array}$ \\
\hline & Visão Sistêmica & $\begin{array}{l}\text { É a capacidade de perceber a integração e a } \\
\text { interdependência de assuntos diversos que contribuem } \\
\text { para uma maior eficácia do processo ensino- } \\
\text { aprendizagem. }\end{array}$ \\
\hline & Comunicação & $\begin{array}{l}\text { É a capacidade de ouvir, processar, compreender e } \\
\text { expressar-se de diversas formas e usar o feedback de } \\
\text { forma adequada para facilitar a interação com seus } \\
\text { alunos. }\end{array}$ \\
\hline & Liderança & $\begin{array}{l}\text { É a capacidade de incentivar e influenciar seus alunos a } \\
\text { atingirem ou superarem seus objetivos pessoais do seu } \\
\text { processo de aprendizagem. }\end{array}$ \\
\hline & Planejamento & $\begin{array}{l}\text { É a capacidade de planejar e organizar as diversas } \\
\text { atividades do processo ensino-aprendizagem. }\end{array}$ \\
\hline \multirow{5}{*}{ Atitudes } & Comprometimento & $\begin{array}{l}\text { É o comportamento relacionado com o nível de } \\
\text { envolvimento na obtenção de resultados positivos } \\
\text { nos processos ensino-aprendizagem sob a sua } \\
\text { responsabilidade. }\end{array}$ \\
\hline & Ética & $\begin{array}{l}\text { É o comportamento orientado por princípios e valores } \\
\text { universais de cidadania, em especial na relação com } \\
\text { seus alunos. }\end{array}$ \\
\hline & Pró-atividade & $\begin{array}{l}\text { É o comportamento relacionado ao ato de praticar } \\
\text { ações concretas por iniciativa pessoal para aprimorar o } \\
\text { processo ensino-aprendizagem. }\end{array}$ \\
\hline & Empatia & $\begin{array}{l}\text { É a capacidade de se colocar no lugar do aluno, e, a } \\
\text { partir disso, criar uma relação de confiança e harmonia } \\
\text { que conduza a um maior grau de abertura, por parte } \\
\text { dos estudantes, para aceitar conselhos e sugestões. }\end{array}$ \\
\hline & Flexibilidade & $\begin{array}{l}\text { É a capacidade de adaptar-se a novas situações e de } \\
\text { rever posturas, quando necessário, na sua atuação no } \\
\text { processo de ensino-aprendizagem. }\end{array}$ \\
\hline
\end{tabular}

Fonte: adaptado de Durand (1998), Pereira (2007) e Antonelli et al. (2012).

Na Tabela 1, apresentam-se as competências necessárias à atividade docente. As dimensões são: (i) Conhecimento; (ii) Habilidades; e (iii) Atitudes. Essas dimensões da avaliação da competência seguem a corrente americana (Grohmann \& Ramos, 2012). Para cada uma das dimensões, são apresentados os critérios para a avaliação de cada competência. 


\section{Metodologia da Pesquisa}

O presente estudo possui as seguintes classificações metodológicas: (i) do ponto de vista de seus objetivos, como descritivo, pois os fatos são observados, registrados, analisados, classificados e interpretados, sem a interferência do pesquisador; (ii) quanto aos meios de investigação utilizam-se métodos não experimentais por não se manipularem as variáveis diretamente; (iii) quanto à abordagem do problema, caracteriza-se como um estudo quantitativo, uma vez que técnicas estatísticas são utilizadas nos dados coletados; e, por último, (iv) em relação aos procedimentos de pesquisa, é utilizado o estudo de campo (Cooper \& Schindler, 2003; Hair, Babin, Money \& Samouel, 2005).

Para a operacionalização do presente trabalho, foi replicado o questionário do estudo Antonelli et al. (2012), originado do estudo de Pereira (2007) e modificado por Vasconcellos (2009). A escolha do questionário citado foi motivada pelos testes e validações já realizadas no instrumento, em razão de possuir aptidão de captar as competências que contribuem para melhorar a compreensão do trabalho dos docentes universitários.

Inicialmente, Pereira (2007) concebeu um modelo de 13 competências necessárias para o papel da docência, uma competência específica para ensino (competência didático-pedagógica) e outra para a pesquisa (competência metodologia científica). Neste estudo, o autor aplicou o instrumento nos docentes do curso de Engenharia Química.

Posteriormente, Vasconcelos (2009) adaptou e replicou o modelo proposto por Pereira (2007) para os professores do curso de Ciências Contábeis. As adaptações realizadas por Vasconcelos (2009) refletemse na diferença da realidade dos docentes do curso de Engenharia Química com os de Ciências Contábeis. Assim, foram incluídos dois atributos ao instrumento inicial: (i) capacidade de o docente se mostrar disponível para atendimento extraclasse para os alunos (competência comprometimento); e (ii) disponibilidade em fazer autoavaliação do seu trabalho como docente (competência flexibilidade). No estudo de Vasconcelos (2009), gerou-se o instrumento compreendido de 27 assertivas, todas do tipo Likert adaptada, com onze níveis variando de " 0 " (não possui) a "10" (possui totalmente) para medir o grau de intensidade das competências docentes.

Com o objetivo de capturar as expectativas e satisfações dos discentes do curso de Ciências Contábeis, e não mais dos docentes, Antonelli et al. (2012) realizaram adaptações no instrumento de Vasconcellos (2009), o qual foi aplicado em três universidades públicas do Brasil. Portanto, a coleta de dados ocorreu por meio da replicação do instrumento de Antonelli et al. (2012), com adaptações no bloco em que diz respeito às características dos respondentes, devido à pesquisa anterior ter sido aplicada em três universidades para os últimos dois anos do curso e, no presente estudo, ser aplicado em apenas uma universidade para todos os anos do curso.

Quanto ao instrumento aplicado, ele é subdividido em dois blocos: Caracterização do Respondente e Assertivas de Medição das Expectativas/Satisfação. As alterações realizadas no primeiro bloco foram as seguintes: (i) retirou-se a assertiva que solicitava a instituição do respondente; e (ii) quanto à questão do período cursado pelo acadêmico, acrescentou-se os quatro períodos anuais como opção. As questões que foram mantidas do instrumento original de Antonelli et al. (2012) foram: gênero, idade, trabalha profissionalmente no momento e se já concluiu outra graduação.

Com relação ao segundo bloco, não foram necessárias alterações, de modo que, no estudo de Antonelli et al. (2012), verificaram-se as expectativas e satisfação dos acadêmicos por meio de 24 assertivas, fragmentadas em três dimensões (conhecimentos, habilidades e atitudes), as quais foram decompostas nas seguintes competências docentes: domínio na área de conhecimento; didático-pedagógica; relacionamento interpessoal; trabalho em equipe; criatividade; visão sistêmica; comunicação; liderança; planejamento; comprometimento; ética; pró-atividade; empatia; e flexibilidade. Todas as questões deste bloco são do tipo Likert adaptada, com onze níveis variando de 0 ("não possui") a 10 ("possui totalmente"). Na Tabela 2, estão ilustradas as questões utilizadas, de acordo com as suas dimensões e competências. 
Tabela 2

Instrumento - bloco expectativa/satisfação

\begin{tabular}{|c|c|c|c|}
\hline Dimensões & Competência & Questão & Descrição da questão \\
\hline \multirow{2}{*}{ Conhecimentos } & $\begin{array}{l}\text { Domínio área de } \\
\text { Conhecimento }\end{array}$ & Q01 & Possuírem sólidos conhecimentos das disciplinas ministradas. \\
\hline & Didático-pedagógica & Q02 & $\begin{array}{l}\text { Possuírem conhecimentos fundamentais de conceitos didático- } \\
\text { pedagógicos. }\end{array}$ \\
\hline \multirow{13}{*}{ Habilidades } & \multirow{2}{*}{$\begin{array}{l}\text { Relacionamento } \\
\text { interpessoal }\end{array}$} & Q03 & $\begin{array}{l}\text { Estabelecerem um relacionamento harmônico e saudável com seus } \\
\text { alunos. }\end{array}$ \\
\hline & & Q04 & $\begin{array}{l}\text { Administrarem de forma equilibrada os eventuais conflitos que } \\
\text { possam surgir na relação com seus alunos }\end{array}$ \\
\hline & Trabalho em equipe & Q05 & $\begin{array}{l}\text { Realizarem atividades de ensino conjuntas com outros docentes } \\
\text { com objetivos comuns }\end{array}$ \\
\hline & Criatividade & Q06 & $\begin{array}{l}\text { Criarem soluções inovadoras nas atividades de ensino sob sua } \\
\text { responsabilidade. }\end{array}$ \\
\hline & \multirow[b]{2}{*}{ Visão Sistêmica } & Q07 & $\begin{array}{l}\text { Perceberem a integração e a interdependência entre um assunto } \\
\text { ensinado e demais assuntos de um curso de graduação. }\end{array}$ \\
\hline & & Q08 & $\begin{array}{l}\text { Refletirem com seus alunos sobre a relação entre aquilo que estão } \\
\text { aprendendo e aspectos globais da ciência e/ou da sociedade como } \\
\text { um todo. }\end{array}$ \\
\hline & \multirow{2}{*}{ Comunicação } & Q09 & $\begin{array}{l}\text { Ouvirem, processarem e compreenderem as diferentes } \\
\text { necessidades dos alunos e fornecerem feedback adequado. }\end{array}$ \\
\hline & & Q10 & $\begin{array}{l}\text { Expressarem bem, em especial, de forma oral, de modo que } \\
\text { possam ser facilmente compreendidos pelos seus alunos. }\end{array}$ \\
\hline & \multirow{2}{*}{ Liderança } & Q11 & $\begin{array}{l}\text { Incentivarem os seus alunos a atingirem ou superarem seus } \\
\text { objetivos pessoais no seu processo de aprendizagem. }\end{array}$ \\
\hline & & Q12 & $\begin{array}{l}\text { Influenciarem os seus alunos em relação as suas responsabilidades } \\
\text { pessoais no seu processo de aprendizagem. }\end{array}$ \\
\hline & \multirow{3}{*}{ Planejamento } & Q13 & $\begin{array}{l}\text { Saberem elaborar programas e planos de curso de disciplinas da } \\
\text { graduação. }\end{array}$ \\
\hline & & Q14 & Saberem preparar material didático de apoio às atividades do curso. \\
\hline & & Q15 & $\begin{array}{l}\text { Organizarem a sequência lógica das atividades de cada aula } \\
\text { lecionada. }\end{array}$ \\
\hline \multirow{9}{*}{ Atitudes } & \multirow{2}{*}{ Comprometimento } & Q16 & $\begin{array}{l}\text { Comprometerem-se com a obtenção de resultados positivos nas } \\
\text { atividades de ensino sob sua responsabilidade. }\end{array}$ \\
\hline & & Q17 & $\begin{array}{l}\text { Mostrarem-se disponíveis para atendimento extraclasse para os } \\
\text { alunos. }\end{array}$ \\
\hline & \multirow{2}{*}{ Ética } & Q18 & Demonstrarem respeito pelos seus alunos. \\
\hline & & Q19 & Utilizarem um critério único de avaliação para todos os seus alunos. \\
\hline & Proatividade & Q20 & $\begin{array}{l}\text { Terem iniciativa pessoal de praticar ações concretas que } \\
\text { contribuam para o aprimoramento do processo educacional de } \\
\text { uma forma geral. }\end{array}$ \\
\hline & \multirow{2}{*}{ Empatia } & Q21 & $\begin{array}{l}\text { Criarem uma relação de confiança e harmonia com seus alunos } \\
\text { que conduzam a um maior grau de abertura deles (docentes) para } \\
\text { aceitar conselhos e sugestões. }\end{array}$ \\
\hline & & Q22 & $\begin{array}{l}\text { Colocarem-se no lugar do aluno e tentarem compreender o seu } \\
\text { comportamento pessoal, visando poder auxiliá-lo a ser mais } \\
\text { produtivo no seu aprendizado. }\end{array}$ \\
\hline & \multirow{2}{*}{ Flexibilidade } & Q23 & $\begin{array}{l}\text { Adaptarem-se a novas situações quando necessário frente a novos } \\
\text { desafios nos processos de ensino nos quais atua. }\end{array}$ \\
\hline & & Q24 & $\begin{array}{l}\text { Estarem dispostos a rever o processo de ensino com base em } \\
\text { resultados de avaliações efetuadas. }\end{array}$ \\
\hline
\end{tabular}

Fonte: adaptada de Pereira (2007); Vasconcellos (2009) e Antonelli et al. (2012) 
Após a obtenção da versão final do instrumento, iniciou-se a realização da coleta dos dados, por meio de visitas realizadas durante as aulas da graduação, no período de 10/01/2013 até 31/01/2013. Primeiramente, foi explicado aos respondentes o objetivo da pesquisa e distribuído o questionário impresso. Foram obtidas 92 respostas válidas, constituindo-se na amostra final desta pesquisa. Antes de iniciar as análises estatísticas no instrumento, Field (2009) cita a importância de checar a confiabilidade da escala. Nesse sentido, optou-se pelo coeficiente Alfa de Cronbach, com valor ideal mínimo de 0,7, podendo ser aceito 0,6 para pesquisas exploratórias (Hair, Black, Babin, Anderson \& Tatham, 1998).

$\mathrm{Na}$ verificação da confiabilidade de escala, por meio do coeficiente Alfa de Cronbach, primeiramente, foi aplicado o teste nas assertivas da satisfação e, posteriormente, nas de expectativas. Nas 24 assertivas que medem a satisfação discente, o coeficiente obtido foi de 0,947 , valor aceitável que demonstra a confiabilidade do modelo. Nas assertivas das expectativas, obteve-se o coeficiente 0,962 , valor também aceitável. É importante salientar que o pressuposto do coeficiente de Alfa de Cronbach foi atendido em ambas as situações (correlações entre os itens devem ser positivas). No estudo de Antonelli et al. (2012), os valores obtidos do coeficiente Alfa de Cronbach também foram elevados, com 0,943 na satisfação discente e 0,859 nas expectativas, reforçando a confiabilidade de escala do modelo.

A análise estatística ocorreu em três passos: (i) Avaliação da Normalidade e Homogeneidade das Variâncias; (ii) Avaliação das Competências mais bem avaliadas das piores avaliadas; e (iii) Comparação das Competências segregando a Amostra em Turma e Gênero.

\section{Análise dos Resultados}

\subsection{Caracterização da amostra}

Com o objetivo de medir o grau de intensidade da satisfação e das expectativas discentes em relação às competências docentes, os acadêmicos do curso de Ciências Contábeis na UTFPR - Campus Pato Branco foram questionados. Na aplicação do instrumento de pesquisa, algumas características da amostra são ressaltadas a seguir. Das 92 respostas válidas obtidas, a segregação dos acadêmicos por turma é a seguinte: 18 respondentes do $1^{\circ}$ ano (com 19,6\% de representatividade); 24 do $2^{\circ}$ ano (26,1\%); 23 do $3^{\circ}$ ano (25,0\%); e por último, 27 alunos do $4^{\circ}$ ano $(29,3 \%)$. Nessa divisão da amostra, pode-se observar que as quatro turmas possuem número de elementos próximos.

Em relação ao gênero dos entrevistados, a maioria dos respondentes são mulheres com uma porcentagem expressiva sobre os homens, o que não era comum há alguns anos. As mulheres representaram $67,4 \%$ dos respondentes e os homens, apenas $32,6 \%$. A faixa etária também foi alvo de análise, sendo que a maioria dos respondentes possui de 20 a 25 anos, representando $66,3 \%$ da amostra. As demais idades tiveram os seguintes resultados: até 19 anos (21,7\%); 26 a 30 anos (7,6\%); 31 a 35 anos (3,3\%); e acima de 46 anos $(1,1 \%)$.

Outro ponto observado foi a alta incidência da realização de atividades paralelas à graduação, com 87 acadêmicos, que representam $94,6 \%$ da amostra. Com relação aos discentes que trabalham na área, observa-se que 69,6\% (64) atuam na área contábil. Referindo-se ao motivo que levou à escolha do curso de Ciências Contábeis, a maioria respondeu que a escolha seu deu pelas oportunidades que o curso proporciona (70,7\%). A última questão para a caracterização dos respondentes foi a de possuírem, ou não, outra graduação. Verificou-se que 84 alunos respondentes (91,3\%) não possuem outra graduação, sendo que apenas oito discentes possuem outra graduação, sendo curso de Administração (5 pessoas), Geografia (1), Sistema de Informação (1) e Técnico em Enfermagem (1).

Após a análise das assertivas de caracterização dos respondentes, observa-se que, em geral, são mulheres, na faixa etária entre 20 a 25 anos, sendo que a maioria já atua na área contábil, e a escolha do curso se deu pelas oportunidades que ele proporciona. 


\subsection{Análise das competências docentes}

Para realizar a análise das competências foi calculada a média e o desvio médio de cada competência, separadas no grupo satisfação e expectativas, conforme apresentado na Tabela 3.

Tabela 3

Médias e desvios médios das competências

\begin{tabular}{|c|c|c|c|c|c|}
\hline \multicolumn{3}{|c|}{ Satisfação } & \multicolumn{3}{|c|}{ Expectativas } \\
\hline Competência & Média & Desvio médio & Competência & Média & Desvio médio \\
\hline Domínio da área & 7,6 & 0,9 & Domínio da área & 9,4 & 0,7 \\
\hline Didático-pedagógica & 7,3 & 1,0 & Didático-pedagógica & 9,2 & 0,7 \\
\hline $\begin{array}{l}\text { Relacionamento } \\
\text { interpessoal }\end{array}$ & 7,9 & 0,9 & $\begin{array}{l}\text { Relacionamento } \\
\text { interpessoal }\end{array}$ & 9,2 & 0,7 \\
\hline Trabalho em equipe & 5,4 & 1,9 & Trabalho em equipe & 8,4 & 1,4 \\
\hline Criatividade & 5,7 & 1,7 & Criatividade & 8,8 & 1,1 \\
\hline Visão sistêmica & 7,0 & 1,1 & Visão sistêmica & 9,0 & 0,8 \\
\hline Comunicação & 6,7 & 1,1 & Comunicação & 9,3 & 0,7 \\
\hline Liderança & 6,9 & 1,2 & Liderança & 9,0 & 0,8 \\
\hline Planejamento & 6,9 & 1,1 & Planejamento & 9,2 & 0,7 \\
\hline Comprometimento & 7,7 & 1,0 & Comprometimento & 9,4 & 0,6 \\
\hline Ética & 7,5 & 1,0 & Ética & 9,3 & 0,7 \\
\hline Proatividade & 7,2 & 1,3 & Proatividade & 9,2 & 0,8 \\
\hline Empatia & 6,5 & 1,4 & Empatia & 9,0 & 0,9 \\
\hline Flexibilidade & 6,7 & 1,3 & Flexibilidade & 9,3 & 0,8 \\
\hline Total & 6,9 & 1,2 & Total & 9,1 & 0,8 \\
\hline
\end{tabular}

Fonte: elaborada pelos autores.

Pode-se observar que os discentes, em geral, esperam mais de seus docentes (média geral de 9,1), quando comparada à satisfação que experimentam (média 6,9) durante o curso. Verifica-se também a diferença entre os desvios médios que, a princípio, sugerem uma maior dispersão nas respostas relacionadas à satisfação, quando comparadas às expectativas. Na dimensão da satisfação, pelos valores absolutos das médias, é possível verificar algumas competências em que os alunos se dizem mais satisfeitos em relação a outras. Porém, para ser possível essa afirmação, é necessária a realização de testes estatísticos de comparação de médias, os quais são descritos na sequência.

Para a realização da comparação das médias das competências, com o objetivo de ordená-las pela intensidade das respostas, primeiramente os dados foram padronizados, e posteriormente, foi verificada a normalidade e homogeneidade de variância dos dados, por meio dos testes Kolmogorov-Smirnov e Levene, respectivamente. No teste de normalidade, com nível de significância de 5\% para todas as competências, foi aceita a hipótese nula (Ho), relatando a não normalidade dos dados, tanto para as assertivas de satisfação quanto as de expectativas. Em relação ao teste de Levene, observa-se também que os dados não possuem homogeneidade de variâncias. Diante disso, foi necessária a utilização de uma técnica não paramétrica para avaliar a diferença entre as médias. 
O teste não paramétrico de Kruskal-Wallis possibilitou a comparação de dois ou mais grupos amostrais de dados não pareados, no caso, as 14 competências estudadas na perspectiva da satisfação e expectativas discentes. Para os testes das duas perspectivas, foi utilizado nível de significância de $5 \%$ com a hipótese nula da não existência de diferenças estatisticamente significativas entre as médias amostrais. Para a satisfação discente, a hipótese $\mathrm{H}_{0}$ foi rejeitada, comprovando estatisticamente a existência de diferenças entre as médias $[\mathrm{H}(13)=184,80, \mathrm{p}<0,05]$. Para as expectativas, também se encontraram diferenças estatísticas $[\mathrm{H}(13)=34,76, \mathrm{p}<0,05]$, rejeitando $\mathrm{H}_{0}$.

A etapa seguinte foi a aplicação de testes de hipóteses post hoc para verificar quais médias são estatisticamente diferentes. A opção foi pelo teste de hipóteses de Mann-Whitney, com aplicação da correção de Bonferroni em todos os efeitos, com um nível de significância de 0,0083 [0,05/6]. Na Tabela 4 são relacionadas as competências ordenadas pelo ranqueamento obtido pelo teste Kruskal-Wallis, e suas respectivas diferenças.

Tabela 4

Ranqueamento das competências com relação à satisfação discente

\begin{tabular}{|c|c|c|c|c|c|c|c|c|c|c|c|c|c|c|c|}
\hline $\begin{array}{c}\text { Satisfação } \\
\text { Discente }\end{array}$ & 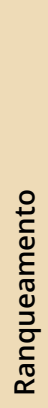 & 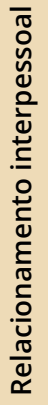 & 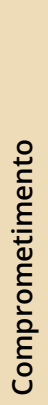 & 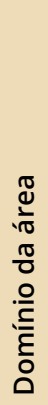 & 芜 & 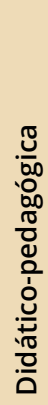 & $\begin{array}{l}\frac{0}{0} \\
\frac{\pi}{0} \\
\frac{0}{2} \\
\frac{1}{\pi} \\
\frac{0}{0}\end{array}$ & $\begin{array}{l}\stackrel{0}{U} \\
\frac{c}{d} \\
\frac{E}{\sigma} \\
\frac{D}{D} \\
\frac{c}{\sigma} \\
\frac{\sigma}{a}\end{array}$ & 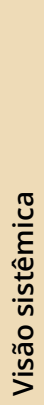 & $\begin{array}{l}\text { U্ } \\
\frac{c}{0} \\
\frac{0}{d} \\
\frac{0}{3}\end{array}$ & 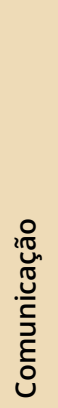 & $\begin{array}{l}\frac{0}{0} \\
\frac{\pi}{0} \\
\frac{\underline{0}}{\overline{0}} \\
\frac{\bar{x}}{\alpha} \\
\frac{0}{4}\end{array}$ & $\begin{array}{l}\stackrel{0}{\frac{\pi}{\sigma}} \\
\text { 을 } \\
\text { 岀 }\end{array}$ & $\begin{array}{l}\frac{0}{0} \\
\frac{\pi}{0} \\
\frac{0}{2} \\
. \frac{\pi}{2} \\
\frac{\pi}{2}\end{array}$ & 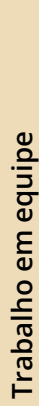 \\
\hline Ranqueamento & & + & & & & & r Ra & ue e & Men & Rar & que & & & & - \\
\hline $\begin{array}{l}\text { Relacionamento } \\
\text { interpessoal }\end{array}$ & + & & $=$ & $=$ & $=$ & $=$ & $\neq$ & $\neq$ & $\neq$ & $\neq$ & $\neq$ & $\neq$ & $\neq$ & $\neq$ & $\neq$ \\
\hline Comprometimento & \multirow{12}{*}{ 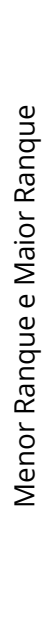 } & $=$ & & $=$ & $=$ & $=$ & $=$ & $\neq$ & $\neq$ & $\neq$ & $\neq$ & $\neq$ & $\neq$ & $\neq$ & $\neq$ \\
\hline Domínio da área & & $=$ & $=$ & & $=$ & $=$ & $=$ & $=$ & $=$ & $=$ & $\neq$ & $\neq$ & $\neq$ & $\neq$ & $\neq$ \\
\hline Ética & & $=$ & $=$ & $=$ & & $=$ & $=$ & $=$ & $=$ & $=$ & $=$ & $\neq$ & $\neq$ & $\neq$ & $\neq$ \\
\hline Didático-pedagógica & & $=$ & $=$ & $=$ & $=$ & & $=$ & $=$ & $=$ & $=$ & $=$ & $=$ & $=$ & $\neq$ & $\neq$ \\
\hline Proatividade & & $\neq$ & $=$ & $=$ & $=$ & $=$ & & $=$ & $=$ & $=$ & $=$ & $=$ & $=$ & $\neq$ & $\neq$ \\
\hline Planejamento & & $\neq$ & $\neq$ & $=$ & $=$ & $=$ & $=$ & & $=$ & $=$ & $=$ & $=$ & $=$ & $\neq$ & $\neq$ \\
\hline Visão sistêmica & & $\neq$ & $\neq$ & $=$ & $=$ & $=$ & $=$ & $=$ & & $=$ & $=$ & $=$ & $=$ & $\neq$ & $\neq$ \\
\hline Liderança & & $\neq$ & $\neq$ & $=$ & $=$ & $=$ & $=$ & $=$ & $=$ & & $=$ & $=$ & $=$ & $\neq$ & $\neq$ \\
\hline Comunicação & & $\neq$ & $\neq$ & $\neq$ & $=$ & $=$ & $=$ & $=$ & $=$ & $=$ & & $=$ & $=$ & $=$ & $=$ \\
\hline Flexibilidade & & $\neq$ & $\neq$ & $\neq$ & $\neq$ & $=$ & $=$ & $=$ & $=$ & $=$ & $=$ & & $=$ & $=$ & $=$ \\
\hline Empatia & & $\neq$ & $\neq$ & $\neq$ & $\neq$ & $=$ & $=$ & $=$ & $=$ & $=$ & $=$ & $=$ & & $=$ & $=$ \\
\hline Criatividade & & $\neq$ & $\neq$ & $\neq$ & $\neq$ & $\neq$ & $\neq$ & $\neq$ & $\neq$ & $\neq$ & $=$ & $=$ & $=$ & & $=$ \\
\hline Trabalho em equipe & 1 & $\neq$ & $\neq$ & $\neq$ & $\neq$ & $\neq$ & $\neq$ & $\neq$ & $\neq$ & $\neq$ & $=$ & $=$ & $=$ & $=$ & \\
\hline
\end{tabular}

Fonte: elaborada pelos autores. 
De acordo com a Tabela 4, é possível ordenar as competências docentes mais bem avaliadas das piores avaliadas em relação à satisfação discente, na ordem: relacionamento interpessoal; comprometimento; domínio da área; ética; didático-pedagógica; proatividade; planejamento; visão sistêmica, liderança; comunicação; flexibilidade, empatia; criatividade; e trabalho em equipe. Das cinco competências mais bem avaliadas, observa-se na Tabela 4 a igualdade estatística entre elas, ou seja, a satisfação dos discentes em relação a elas é estatisticamente igual. Já a sexta competência (proatividade) tem diferença estatística da primeira, a mais bem avaliada, o relacionamento interpessoal. Nesse raciocínio, na Tabela 4, é possível observar que as competências ranqueadas no meio da matriz diferem das ranqueadas nos extremos. Já as cinco competências com pior avaliação também possuem médias estatisticamente iguais, porém, diferentes das mais bem avaliadas.

Portanto, sumarizando as informações da Tabela 4, observa-se que os discentes estão mais satisfeitos com seus docentes nas seguintes competências: relacionamento interpessoal; comprometimento; domínio da área; ética; e didático-pedagógica. Em contrapartida, os alunos possuem menor satisfação nas seguintes competências: comunicação; flexibilidade; empatia; criatividade; e trabalho em equipe.

Com a utilização da mesma técnica estatística da satisfação discentes, foi realizada a análise das expectativas discentes, conforme Tabela 5 .

Tabela 5

Ranqueamento das competências com relação às expectativas discentes

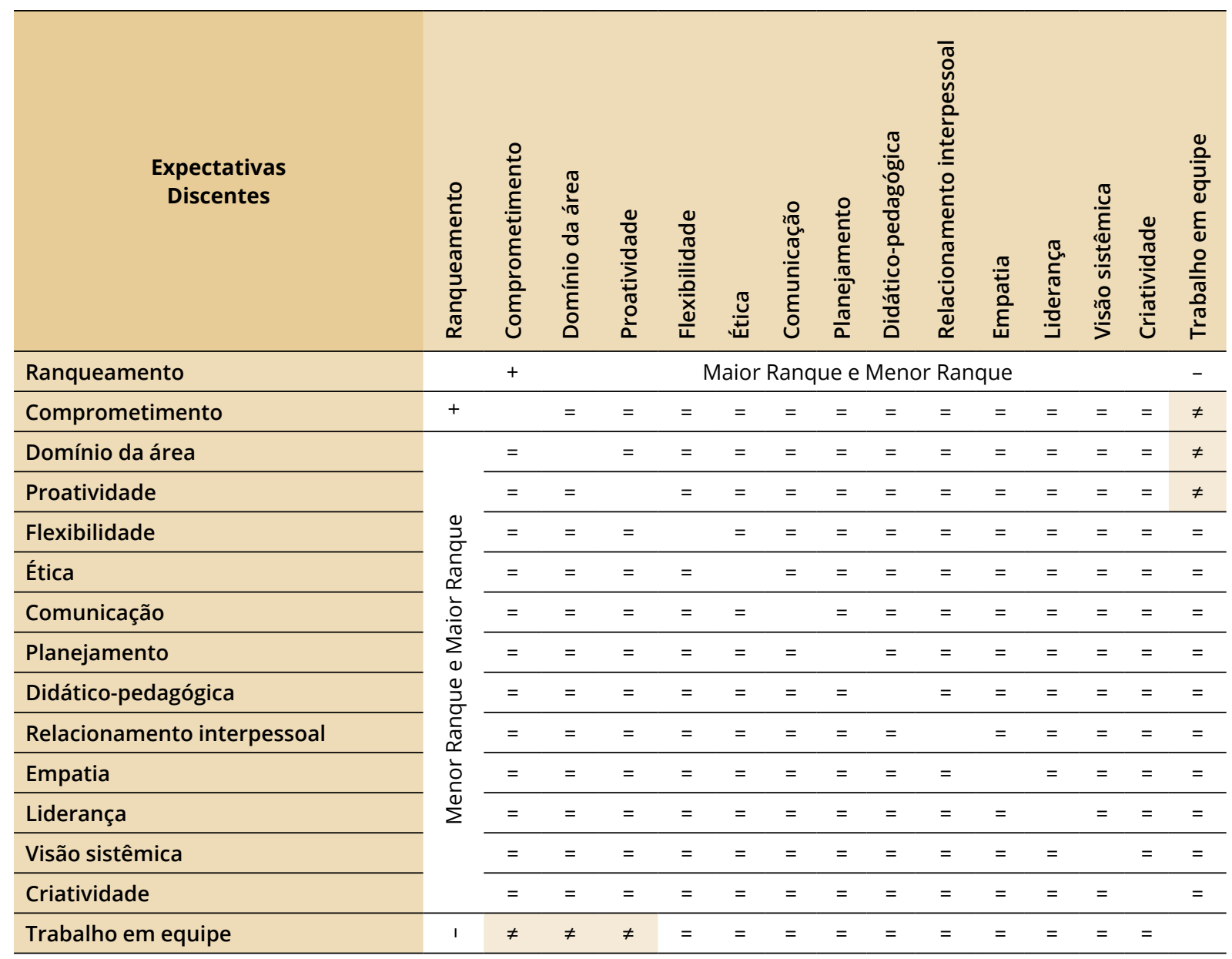

Fonte: elaborada pelos autores. 
Diferentemente da satisfação discente, as expectativas possuem maior similaridade entre as competências. Na Tabela 5, observa-se apenas uma expectativa menor do trabalho de equipe quando comparado ao comprometimento, domínio da área e proatividade. Todas as outras comparações não revelaram diferenças estatísticas.

\subsection{Análise das competências docentes segregadas por turma e gênero}

Com a segregação da amostra em grupos, de acordo com as assertivas de caracterização do respondente da turma e do gênero, visou-se avaliar a possível existência de diferença estatística entre as turmas e os gêneros.

Primeiramente, aplicou-se o teste Kruskal-Wallis separando a amostra em quatro grupos, representados pelas quatro turmas pesquisadas. Com relação à satisfação discente, a hipótese $\mathrm{H}_{0}$ foi aceita para todas as competências, revelando a inexistência de diferença estatística entre as turmas. Também foi segregada a amostra em gênero, a fim de verificar as diferenças, o que também não foi detectado. Com isso, observa-se que a satisfação discente em relação às competências não tem variação entre turmas e gêneros.

Com a mesma metodologia de aplicação do teste Kruskal-Wallis para a satisfação, foi utilizado nas expectativas discentes. No agrupamento entre turmas, não foram detectadas diferenças estatísticas. Porém, com relação ao gênero, algumas diferentes estatísticas foram detectadas, rejeitando $\mathrm{H}_{0}$, conforme Tabela 6 .

Tabela 6

Comparação das expectativas discentes com relação às competências - segregação por gênero

\begin{tabular}{|c|c|c|c|}
\hline Dimensão & Competência & $\begin{array}{l}\text { Resultado teste Kruskal- } \\
\text { Wallis - Grupo Gênero }\end{array}$ & $\begin{array}{l}\text { Gênero com maior } \\
\text { Expectativa }\end{array}$ \\
\hline \multirow{2}{*}{ Conhecimento } & Domínio da área & $=$ & Igual \\
\hline & Didático-pedagógica & $=$ & Igual \\
\hline \multirow{7}{*}{ Habilidade } & $\begin{array}{l}\text { Relacionamento } \\
\text { interpessoal }\end{array}$ & $=$ & Igual \\
\hline & Trabalho em equipe & $=$ & Igual \\
\hline & Criatividade & $=$ & Igual \\
\hline & Visão sistêmica & $\neq$ & Feminino \\
\hline & Comunicação & $=$ & Igual \\
\hline & Liderança & $\neq$ & Feminino \\
\hline & Planejamento & $\neq$ & Feminino \\
\hline \multirow{5}{*}{ Atitude } & Comprometimento & $\neq$ & Feminino \\
\hline & Ética & $\neq$ & Feminino \\
\hline & Proatividade & $\neq$ & Feminino \\
\hline & Empatia & $\neq$ & Feminino \\
\hline & Flexibilidade & $\neq$ & Feminino \\
\hline
\end{tabular}

Fonte: Elaborado pelos autores.

Como se observa na Tabela 6, quando as expectativas divergem entre os gêneros, verificou-se que sempre o feminino tem maior expectativa, ou seja, é provável, que as mulheres esperam mais de seus docentes. Outro fator relevante é que as expectativas não são diferentes nas competências da dimensão conhecimento, porém, em todas as competências da dimensão atitude, estas divergem, além das diferenças em três competências da dimensão habilidade. 


\subsection{Comparação dos resultados obtidos com pesquisas precedentes}

Os resultados, aqui, obtidos foram comparados com estudos precedentes. Tais checagens são relacionadas à satisfação discente. Os estudos-alvo de comparação são Vasconcelos (2009) e Antonelli et al. (2012). As comparações entre os resultados apontados nos estudos encontram-se na Tabela 7.

Tabela 7

Comparação dos resultados com os estudos de Vasconcelos (2009) e Antonelli et al. (2012).

\begin{tabular}{llllcc}
\hline \multicolumn{1}{c}{ Competências } & \multicolumn{1}{c}{ Questões } & $\begin{array}{c}\text { Média do estudo de } \\
\text { Vasconcelos (2009) }\end{array}$ & $\begin{array}{c}\text { Média } \\
\text { Antonelli } \text { et. al } \\
\text { (2012) (A) }\end{array}$ & $\begin{array}{c}\text { Média } \\
\text { Presente } \\
\text { Estudo (B) }\end{array}$ & $\begin{array}{c}\text { Diferença } \\
\text { (B-A) }\end{array}$ \\
\hline Domínio área do Conhec. & Q01 & 8,0 & 6,7 & 7,6 & 0,9 \\
\hline Didático-pedagógico & Q02 & 7,9 & 6,1 & 7,3 & 1,2 \\
\hline Relacionamento Interpessoal & Q03 e Q04 & 9,1 & 6,7 & 7,9 & 1,2 \\
\hline Trabalho em Equipe & Q05 & 8,2 & 4,5 & 5,4 & 0,9 \\
\hline Criatividade & Q06 & 8,4 & 4,9 & 5,7 & 0,9 \\
\hline Visão Sistêmica & Q07 e Q08 & 8,8 & 6,0 & 7,0 & 1,0 \\
\hline Comunicação & Q09 e Q10 & 8,8 & 5,6 & 6,7 & 1,1 \\
\hline Liderança & Q11 e Q12 & 9,0 & 5,9 & 6,9 & 1,0 \\
\hline Planejamento & Q13 e Q14 e Q15 & 9,0 & 6,1 & 6,9 & 0,8 \\
\hline Comprometimento & Q16 e Q17 & 9,1 & 6,1 & 7,7 & 1,6 \\
\hline Ética & Q18 e Q19 & 9,2 & 7,5 & 7,5 & 0,0 \\
\hline Proatividade & Q20 & 8,6 & 5,9 & 7,2 & 1,4 \\
\hline Empatia & Q21 e Q22 & 9,0 & 5,6 & 6,5 & 0,9 \\
\hline Flexibilidade & Q23 e Q24 & 9,1 & 5,6 & 6,7 & 1,1 \\
\hline Média Geral & & 8,7 & 5,9 & 6,9 & 1,0 \\
\hline
\end{tabular}

Fonte: elaborada pelos autores.

É importante salientar que a comparação com o estudo de Vasconcelos (2009) não é possível ser realizada de forma completa, devido ao fato de o autor ter aplicado o instrumento nos docentes, enquanto na presente pesquisa foi aplicado aos discentes, o qual buscou capturar a relação docente/competência. Observa-se nos resultados do estudo citado que os docentes consideram estar mais alinhados com as competências, pois todas as competências tiveram médias superiores quando comparadas ao estudo de Antonelli et al. (2012) e o presente estudo, ambos aplicados aos discentes.

Na comparação entre a presente pesquisa com a de Antonelli et al. (2012), observa-se que, em todas as competências, a satisfação discente desta pesquisa obteve maiores médias, com exceção da competência ética que, em ambos os estudos, tiveram média 7,5. As maiores diferenças entre os estudos estão no comprometimento e na pró-atividade. Uma possível explicação para as divergências detectadas pode ser explicada pelas divergências das amostras dos estudos, tendo em vista que o presente estudo pesquisou os discentes apenas da UTFPR - Campus Pato Branco, em todas as turmas do curso, enquanto o estudo precedente questionou os acadêmicos dos dois últimos anos de três universidades federais.

No estudo precedente, verificou-se que os discentes estão mais satisfeitos quanto à ética $(7,41) \mathrm{e}$ domínio na área do conhecimento $(6,69)$ e ainda menos satisfeitos com trabalho em equipe $(4,48)$ e criatividade $(4,85)$. No atual estudo, os alunos estão mais satisfeitos com o relacionamento interpessoal $(7,91)$ e domínio na área de conhecimento $(7,58)$ e menos satisfeitos com as mesmas competências do estudo anterior, que são o trabalho em equipe e a criatividade. 


\section{Conclusão}

O presente trabalho teve por objetivo identificar qual o nível de satisfação e expectativa dos alunos do curso de Ciências Contábeis da UTFPR - Campus de Pato Branco em relação aos seus docentes. Para tanto, aplicou-se um questionário com questões objetivas e fechadas para todos os alunos do curso, a fim de avaliar as satisfações e expectativas discentes. Além disso, questões de caracterização dos respondentes foram submetidas à amostra.

A pesquisa constatou que os acadêmicos esperam mais de seus professores, pois a média que se refere à satisfação ficou inferior à média das expectativas. Quanto à satisfação discente, observou-se que as competências relacionamento interpessoal, comprometimento, domínio da área, ética e didático-pedagógica foram as mais bem avaliadas, sem diferença estatística entre elas. Entre as competências mais bem avaliadas, observa-se que as duas representantes da dimensão "Conhecimento" estão entre as cinco mais bem avaliadas, o que sugere alunos mais satisfeitos com o conhecimento técnico de seus professores.

Entre as competências com pior avaliação, tem-se a comunicação, flexibilidade, empatia, criatividade e trabalho em equipe. Isso sugere discentes com menor satisfação nas competências das dimensões Habilidade e Atitude, o que pode ser explicado pela falta de preparo didático-pedagógico de seus docentes, haja vista que a grande maioria dos cursos de Ciências Contábeis não possui foco no preparo de docentes. Nesse sentido, também é relatada na pesquisa a baixa satisfação na competência trabalho de equipe.

Portanto, de acordo com os resultados obtidos na satisfação discente, sugere-se aos docentes uma melhor comunicação com os alunos, flexibilidade em algumas situações, empatia no sentido de o docente se colocar no lugar do aluno, estimular atividades/trabalhos em grupos, e, por último, tentar inovar as aulas, utilizando atividades criativas para despertar o interesse do aluno na disciplina. Tais constatações estão alinhadas ao estudo de Lima Filho e Bruni (2012), que indicam que os docentes da disciplina Teoria da Contabilidade devem investir maiores esforços no ajuste de suas agendas didáticas. Além disso, Miranda et al. (2014) concluem sobre a necessidade de conscientização dos próprios docentes sobre a importância da sua qualificação, sendo essa uma das formas de os docentes melhorarem seus desempenhos nas competências aqui pesquisadas.

Com relação às expectativas discentes, observou-se a similaridade entre elas, diferentes da satisfação. A única diferença detectada é na competência do trabalho em equipe, uma vez que os discentes não esperam tanto quando comparadas à maioria das outras competências. Essas similaridades podem ser explicadas pela alta expectativa que os discentes têm, em geral, em todas as competências e dimensões.

$\mathrm{Na}$ comparação da satisfação e expectativas entre as turmas e os gêneros, todos os resultados se mostraram iguais, com exceção das expectativas segregadas pelo gênero. Algumas competências têm maior expectativa que outras e nestas as mulheres possuem maior expectativa. Essa informação sugere uma maior "cobrança" das alunas aos seus docentes, pois elas esperam mais deles em relação às competências necessárias à docência.

Em resumo, a primeira implicação/conclusão importante dos resultados refere-se à baixa divergência do presente estudo com os estudos precedentes. Isso leva à conclusão de que, mesmo com o passar do tempo, permanece-se com os principais problemas relacionados às competências docentes. No entanto, é notória a complexidade da atividade docente e das possibilidades dos gestores na mudança de tal ambiente, mas as evidências reafirmadas no presente estudo indicam a necessidade de muitos aperfeiçoamentos.

A segunda implicação/conclusão relevante dos resultados sugere a necessidade de os professores estarem atentos às competências com piores níveis de satisfação, como a comunicação, flexibilidade, empatia, criatividade e trabalho em equipe. É importante lembrar que tais competências necessitam ser valorizadas pelos professores, igualmente, às de conhecimento.

A terceira implicação/conclusão de destaque refere-se ao nível geral de expectativa do aluno, que é bem superior à satisfação, e isso deve ser considerado pelos professores no planejamento de suas disciplinas. 
A última implicação/conclusão importante refere-se às competências com menor nível de satisfação dos alunos nas dimensões atitudes e habilidades e, não, de conhecimento. Essa conclusão é fundamental para que o professor visualize que o aluno valoriza outras dimensões que não somente o conhecimento, além de servir também para que os cursos e coordenações considerem essas competências adicionais em seu planejamento de capacitações.

Conclui-se pelos resultados obtidos na presente pesquisa, que as universidades devem investir cada vez mais nas competências docentes, de modo a refletir diretamente na qualidade dos cursos oferecidos, com a possibilidade de formar profissionais mais bem qualificados para exercerem a profissão de contador. É importante também que as IES reflitam com seus docentes sobre as competências que tiveram baixa satisfação, para que futuramente possam melhorá-las no intuito de melhor satisfazer aos seus discentes.

No que diz respeito à limitação da pesquisa, é importante ressaltar a impossibilidade de generalização dos resultados obtidos por conta do método de amostragem utilizado, que foi o não probabilístico. Para pesquisas futuras sugere-se a replicação deste estudo para diferentes cursos de graduação e em outras universidades. Também se sugere a verificação de possíveis causas e motivos dos resultados encontrados para se planejar melhorias no curso pesquisado.

\section{Referências}

Antonelli, R. A.; Colauto, R. D.; Cunha, J. V. A. (2012). Expectativa e Satisfação dos Alunos de Ciências Contábeis Com Relação às Competências Docentes. REICE - Revista Iberoamericana sobre Qualidade Eficácia e Mudança em Educação, 10(1) pp. 74-91.

Apio, A. L.; Silvino, A. M. D. (2013). A aula pública como instrumento preditor de desempenho docente no ensino superior. Avaliação (Campinas), 18(2), pp. 277-98. DOI: http://dx.doi.org/10.1590/ S1414-40772013000200003.

Bitencourt, C. C. (2001). A gestão de competências gerenciais: a contribuição da aprendizagem organizacional. Tese de doutorado apresentada no Programa de Pós-Graduação e Pesquisas em Administração da UFRGS, Porto Alegre, RS, Brasil.

Castanheira, A. M.; Ceroni, M. R. (2007). Reflexões sobre o processo de avaliar docente contribuindo com sua formação. Avaliação (Campinas), 12(4), pp. 719-37.

Cooper, D. R.; Schindler, P. S. (2003). Métodos de Pesquisa em Administração. $7^{\text {a }}$ ed. Porto Alegre: Bookman.

Durand, T. (1998). Forms of incompetence. Proceedings of the fourth international conference on competence-based management. Oslo: Norwegian School of Management.

Dutra, J. S. (2008). Competências: conceitos e instrumentos para a gestão de pessoas na empresa moderna. $1^{a}$ ed. São Paulo: Atlas.

Fava de Moraes, Flávio. (2000). Universidade, inovação e impacto socioeconômico. São Paulo Perspec., 14(3), pp. 8-11. DOI: http://dx.doi.org/10.1590/S0102-88392000000300003.

Field, A. (2009). Descobrindo a Estatística usando o SPSS. 2a Ed. Porto Alegre: Artmed.

Filenga, D.; Moura, V. F.; Rama, A. L. F. (2010). Gestão por Competências: Análise Metodológica e Proposição de um Instrumento para Gestão de Pessoas. Encontro Nacional da Associação Nacional de Pós-Graduação e Pesquisa em Administração - ANPAD, São Paulo, SP, Brasil, 34.

Fleury, M. T. L.; Fleury, A. (2001). Construindo o conceito de competência. Revista de Administração Contemporânea, 5(spe), pp. 183-196, DOI: http://dx.doi.org/10.1590/S1415-65552001000500010. 
Grohmann, M. Z.; Ramos, M. S. (2012). Competências docentes como antecedentes da avaliação de desempenho do professor: percepção de mestrandos de administração. Avaliação, 17(1), pp. 65-86. DOI: $\underline{\text { http://dx.doi.org/10.1590/S1414-40772012000100004. }}$

Hair Jr, J. F.; Babin, B.; Money, A. H.; Samouel, P. (2005). Fundamentos de métodos de pesquisa em administração. Porto Alegre: Bookman.

Hair Jr, J. F.; Black, W. C.; Babin, B.; Anderson, R. E.; Tatham, R. L. (1998). Multivariate data analisys. 5a ed. New Jersey: Prentice Hall.

Hamel, G.; Prahalad, C.K. (1995). Competindo pelo futuro: estratégias inovadoras para obter o controle do seu setor e criar os mercados de amanhã. Rio de Janeiro: Campus.

Hipólito, J. A. M. (2000). A gestão da administração salarial em ambientes competitivos: análise de uma metodologia para construção de sistemas de remuneração de competências. Dissertação de mestrado apresentada na Faculdade de Economia, Administração e Contabilidade da USP, São Paulo, SP, Brasil.

Lima, F. D. C; Oliveira, A. C. L; Araújo, T. S.; Miranda, G. J. (2015). O choque com a realidade: dormi contador e acordei professor.... Revista Iberoamericana sobre Calidad, Eficacia y Cambio en Educación - REICE, 13(1), pp. 49-67.

Lima Filho, R. N.; Bruni, A. L. (2012). Percepção dos Graduandos em Ciências Contábeis de Salvador (BA) sobre os Conceitos Relevantes da Teoria da Contabilidade. Revista de Educação e Pesquisa em Contabilidade - RePEC, 6(2), pp. 187-203, DOI: http://dx.doi.org/10.17524/repec.v6i2.176.

Luckesi, C. C. (2002). Avaliação da aprendizagem escolar: estudos e proposições. 14ª Ed. São Paulo: Cortez.

McClelland, D. C. (1973) Testing for competence rather than for "intelligence". American Psychologist, 28(1), pp. 1-14.

McLagan, P. (1997). Competencies: The Next Generation. Training and Development, p. 40-47.

Miranda, G. J.; Casa Nova, S. P. C.; Cornacchione Junior, E. B. (2014). Uma Aplicação da Técnica Delphi no Mapeamento das Dimensões das Qualificações Docentes na Área Contábil. Revista de Educação e Pesquisa em Contabilidade - RePEC, 8(2), pp. 142-158, DOI: http://dx.doi.org/10.17524/repec.v8i2.1009.

Medeiros, A. C. P.; Oliveira, L. M. B. (2009). Análise das competências de ensino relevantes ao bom desempenho docente: um estudo de caso. Encontro Nacional da Associação Nacional de Pós-Graduação e Pesquisa em Administração - ANPAD, São Paulo, SP, Brasil, 33.

Parry, S. B. (1996). The Quest for Competencies. Training, 33(7), pp. 48-54.

Pereira, M. A. C. (2007) Competências para o ensino e a pesquisa: um survey com docentes de engenharia química. Tese de Doutorado, Universidade de São Paulo (USP), São Paulo, São Paulo, Brasil.

Perez, M. I. L. (2005) Competência: uma noção plástica, polissêmica e polimorfa. Práxis Educacional, 1(1), pp. 57-65.

Perrenoud, P. (2000). Construindo Competências. Entrevista de Paola Gentile e Roberta Bencini. Recuperado em 15 maio, 2013, de http://www.unige.ch/fapse/SSE/teachers/perrenoud/php_main/ php 2000/2000 31.html.

Ribeiro, E. A. (2012). As atuais políticas públicas de avaliação para a educação superior e os impactos na configuração do trabalho docente. Avaliação, 17(2), pp. 299-316.

Ruas, R. L.; Antonello, C. S.; Boff, L. H. (2005). Os novos horizontes da gestão: aprendizagem organizacional e competências. Porto Alegre: Bookman. 
Sant’anna, A. S. (2002). Competências individuais requeridas, modernidade organizacional e satisfação no trabalho. Tese de doutorado apresentada na Faculdade de Ciências Econômicas da UFMG, Belo Horizonte, MG, Brasil.

Silva, C. M. (2003). A gestão por competências e sua Influência na Implementação da gestão estratégica de pessoas: estudo de caso. Dissertação de mestrado apresentada à Faculdade de Economia, Administração e Contabilidade da USP, São Paulo, SP, Brasil.

Souza, J. L. (2005). Gestão por Competência e Gestão Estratégica em uma Empresa Pública. Dissertação de Mestrado do Centro de Ciências da Administração Universidade do Estado de Santa Catarina. Florianópolis, SC, Brasil.

Vasconcelos, A. F. (2009). Professores em Ciências Contábeis: um estudo sobre as competências para o exercício da docência nos cursos presenciais no Nordeste Brasileiro. Dissertação de Mestrado da Universidade de Brasília (UnB), Universidade Federal da Paraíba (UFPB), Universidade Federal do Rio Grande do Norte (UFRN), João Pessoa, Paraíba, Brasil.

Zarifin, P. (2001). Objetivo competência: por uma nova lógica. São Paulo: Atlas. 